\title{
Myxopapillary ependymoma of the filum terminale
}

\author{
Varun Kumar • Ravi Shankar Solanki
}

Received: 22 September 2008 /Revised: 15 October 2008 / Accepted: 20 November 2008 / Published online: 20 February 2009

(C) Springer-Verlag 2009

A 3-year-old girl presented with pain and tenderness over the midline of the buttock area after trauma to the sacrococcygeal region and antecedent history of radiating pain in her lower limbs. MRI demonstrated a 3-cm, intensely enhancing, welldefined oval extramedullary intradural filar mass, isointense to the spinal cord on T1-W images and hyperintense on T2-W images in the cauda (Figs. 1 and 2). Histology confirmed an encapsulated intradural myxopapillary ependymoma.

Ependymomas account for $40-60 \%$ of primary spinal cord tumors and almost $50 \%$ occur in the cauda equina region. In

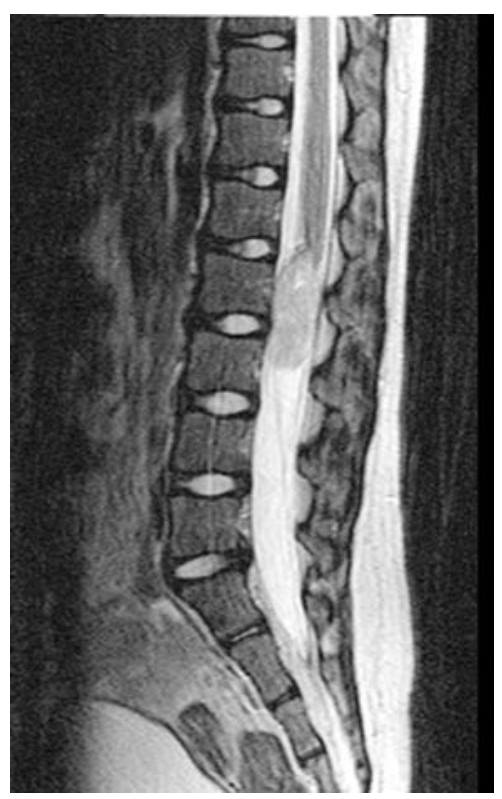

Fig. 1 T2-W sagittal image of the lumbosacral spine

\footnotetext{
V. Kumar $(\bowtie)$

Radiodiagnosis Department, Lady Hardinge Medical College, Connaught Place,

New Delhi, India110001

e-mail: doctorvarunkumar@rediffmail.com
}

\section{R. S. Solanki}

Department of Radiology, Lady Hardinge Medical College, New Delhi, India110001

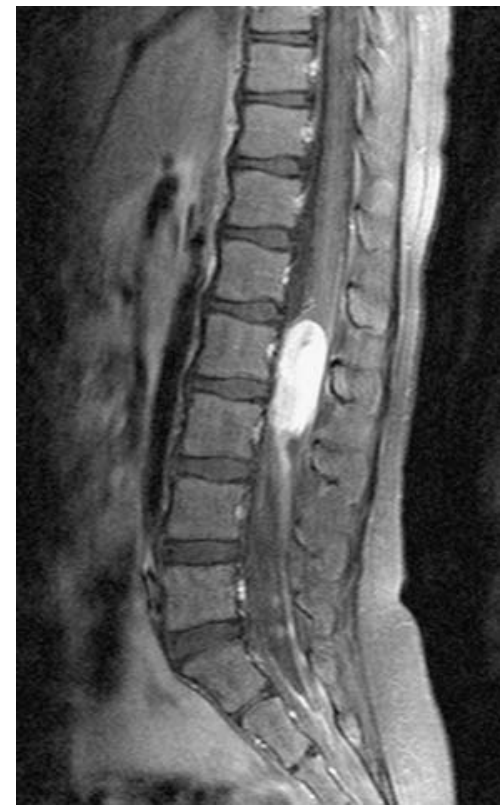

Fig. 2 Gadolinium-enhanced T1-W image

children, $10 \%$ of ependymomas are intraspinal, compared to $75 \%$ in adults. Myxopapillary ependymoma is the most frequent of spinal cord ependymomas and the most vascular subtype of all ependymomas. Multiple lesions may also be seen due to drop metastases (14-43\%), and subarachnoid hemorrhage rarely occurs. The treatment of ependymomas is tumor excision and adjuvant radiotherapy. The prognosis is favorable with a mean survival time of 6 years. Differential diagnosis of filum terminale masses are astrocytoma, hemangioblastoma, lipoma, schwannoma, paraganglioma and metastasis $[1,2]$.

\section{References}

1. Wippold FJ II, Smirniotopoulos JG (1995) MR imaging of myxopapillary ependymoma: findings and value to determine extent of tumour and its relation to intraspinal structures. AJR 165:1263-1267

2. Carragher AM, Heatley MK (1990) A clinicopathological review of spinal ependymomas in Northern Ireland. Ulster Med J 59:51-54 